\title{
Performance enhancement of rotary air preheater by the use of pin shaped turbulators
}

\author{
H. H. Al-Kayiem ${ }^{1}$ \& H. A. A. Mahdi ${ }^{2}$ \\ ${ }^{1}$ Universiti Teknologi PETRONAS, Malaysia \\ ${ }^{2}$ Ministry of Electricity, Baghdad, Iraq
}

\begin{abstract}
The present paper presents the contribution on the performance enhancement study of a regenerative Ljongstrom type air preheater. The experimental analyses are carried out to study the performance enhancement of the system by regular artificial roughening of the heat transfer elements using pin-shaped turbulators (promoters). An experimental test rig is designed and fabricated to simulate the transient operation of the rotary air-preheat system. To study the hydraulic and thermal processes and their combined influences on the system performance, the friction factor and the convection heat transfer coefficient, with and without the turbulators, were evaluated from experimental measurements. The investigations have been carried out under various designs and operational conditions. The results were obtained and presented for Reynolds number in the range of $0.93 \mathrm{x}$ $10^{5}$ to $2.35 \times 10^{5}$ in the thermal discharge period and $0.58 \times 10^{5}$ to $1.8 \times 10^{5}$ in the thermal charging period. The roughening effect was also investigated by varying the pin pitch to pin height ratio, $P / e$; additionally, the effect of the thermal elements numbers in the working section was considered. The artificial roughening by the pins enhanced the performance of the rotary air preheater, and best results have been achieved at $P / e=10$.
\end{abstract}

Keywords: heat transfer enhancement, Rotary air preheater, turbulator, artificial roughened surface, regenerative heat transfer, heat recovery system, thermal experiment.

\section{Introduction}

Heat exchangers (HEX) are devices which provide internal thermal energy transfer between two or more fluids at different temperatures. Common 
examples are the shell-and-tube heat exchangers, automobiles radiators, condensers and evaporators, and pre-heaters for energy recovery. HEX may be classified according to the transfer process, degree of surface compactness, construction features, flow arrangement, number of fluids, fluid phase change, and/or process function. These classifications are widely discussed by Shah [1]. The Ljungstrom rotary air pre-heater (RAPH) is an example of the pre heating exchanger type. An early attempt to study the performance of the heat transfer and fluid flow resistance in Ljungstrom RAPH is presented by Hilmer and Sven [2]. The study was conducted experimentally and theoretically by measuring the pressure drop across the unit using different types of heating elements. Ghodsipour and Sadrameli [3] have simulated the RAPH by developing of a mathematical model. The results were obtained numerically by solving the continuity, the momentum and the energy equations and a two-step, predictor corrector. Skiepko and Shah [4] compared between theoretical model results with directly measured data on a full scale operating air preheater. The results were presented on 3-D charts showing the transient temperature distribution in the rotating matrix. They found that the heat transfer effectiveness is within $\pm 3 \%$ agreement at about $88 \%$ regenerator effectiveness. Another comparison has been presented by $\mathrm{Wu}$ et al [5]. They reported model-based results of a rotary regenerator. Their main focus was on the effect of the inlet air temperature and the geometrical size on the dynamic response of the system. The lack in the experimental results is due to the limitation of their experimental setup, as they concluded. Drobnič et al [6] developed a 3-D mathematical model which enabled the analysis of the flue gas flow through the matrix of the preheater. They have focused on the influence of the leakages on the flue gas parameters. Wang et al [7] have established a theoretical link between the overall efficiency of thermal power plant and the irreversibility in the RAPH. They have changed some design parameters in the system to examine their effect on the plant efficiency and concluded that the leakage in the preheater is an effective factor on the overall plant efficiency.

The enhancement of the heat transfer in thermal systems can be achieved by changing the surface shape of the thermal elements (TE). One of the common techniques is the corrugated plate use as TE. Extensive experimental and analytical investigations were conducted at City University and supported by PowerGen U.K., reported by Stasiek [8]. The flow patterns, the pressure drop, and the local heat transfer coefficient between corrugated surfaces for use in RAPH were presented at various flow angles, shape factors, and Reynolds number. On the use of artificial roughing of the thermal surface, Han and Dutta [9], Han [10] and Webb and Perez-Blanco [11] have conducted numerous experimental and theoretical studies to enhance the heat transfer in gas turbine blades by ribbing the air cooling channels in the blades. Their extensive works have resulted in many correlations on the heat transfer and associated wall friction due to the artificial thermal surface roughening. The book authored by Han et al [12] involves wide range of applications on the field of heat transfer enhancement by artificial roughening. 
The study under consideration was initiated due to the problem associated with the Ljungstrom RAPH in Al-Doura thermal power plant in Baghdad. The corroded original thermal elements (consequently will named TE) were needed to be replaced by locally made ones. The operators of the plant attempted to enhance the performance of the RAPH by increasing the heat transfer surface area. Additional TEs were added to the matrix. This caused reduction in the fluid flow cross-sectional area, which led to high pressure drop in the flue gas and air stream. As a result of that, the amount of the air flow rate was reduced and the combustion process in the furnace was affected considerably. On other side, higher fan power was required to force the flue gases to pass to the stack. Moreover, the accumulation of the ash would block the passages of the gas and air. This might lead to burning and firing in the RAPH unit. Another drawback associated with the increase in TEs is the high weight of the RAPH, which represents additional problem, indeed.

The present work is an experimental investigation on the performance enhancement of RAPH using artificial surface roughening by pin shaped discrete of the TE surface. The measurements were involved the contribution of pins concentration on the surface, the number of TE in the matrix and the flow rates of the working fluids. The results were presented in terms of ratios of the friction factor as indication to the pressure drop, and Stanton number as indication to the thermal performance.

\section{Operational principles of RAPH}

The Ljungstrom RAPH is a storage type heat exchanger. The heat transfer is regenerated in cellular structure referred to as a matrix. Either rotary (as in the present case) or fixed matrix regenerator are commonly used to transfer heat from combustion products to inlet combustion air. This heat is stored in TE of the matrix when it passes through the hot side, or called charging mode period, and when the matrix passes in cold side, or called discharging mode period, it releases the heat to the inlet air. The TE works as thermal energy transfer media between the hot gases and the cold air. The regeneration principles employed in

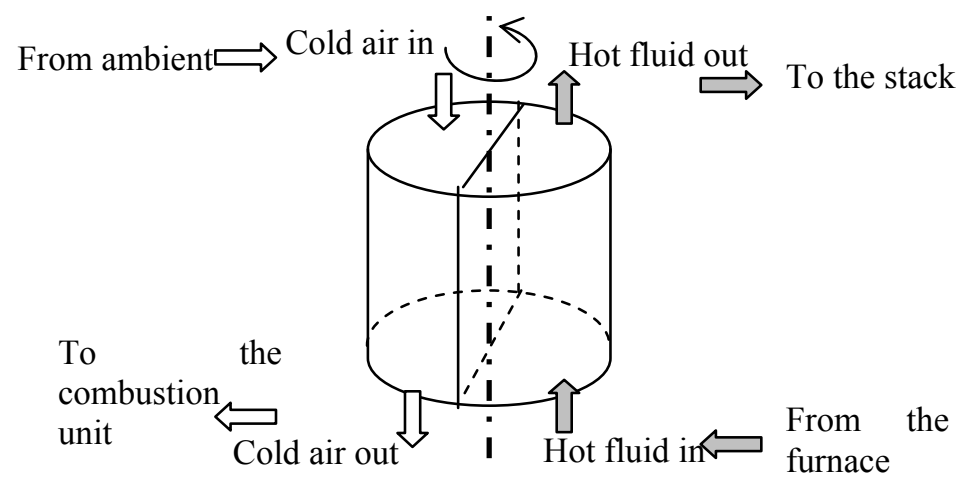

Figure 1: Operational procedure of the RAPH. 
the RAPH consists of a slow-moving rotor packed with closely spaced metal plates or wires, called thermal elements. At each end of the rotor, there is a housing divided by partitions to confine the hot gas to one half of the rotor and the cold gas to the other half, as sketched in figure 1. As the rotor revolves, the temperature of the heating surface increases while passing through the gas compartment and the temperature becomes higher at the end of the period than at the beginning. The rate of increase in the temperature is higher at the beginning than that at the end due to the existence of higher temperature difference in comparison to that at beginning. The release of the heat from the element to the cold air is higher at the beginning of the cold portion of the process.

\section{Experimental apparatus}

An experimental set up has been designed and fabricated to model the actual unit in A-Doura Power Plant. Schematic of the model is shown in figure 2. It consists of a test section, working fluid circulation system, burner unit, and a measuring instrumentation. The test section is a fixed bed heat exchanger designed as a duct with flexible sides to simulate a basket of RAPH. The length of the test section is $1400 \mathrm{~mm}$ with cross-sectional area of $200 \mathrm{~mm} \times 100 \mathrm{~mm}$. The test section is formed by $2 \mathrm{~mm}$ thick steel plates covered with $20 \mathrm{~mm}$ insulation. The core of the test section which simulates a basket of RAPH consists of number of TEs (plates) installed in the same direction of the flow, i.e. parallel arrangement. The test section provides the ability to change the number of the TEs, and consequently, the spacing between the elements could be changed leading to various hydraulic diameters, $D_{h}$. Each heating element is $1 \mathrm{~mm}$ thick. The down part of the test section represents the hot side having lengths of $1100 \mathrm{~mm}$ and width of $200 \mathrm{~mm}$, where the hot air flows up. The upper part of the section represents the cold part with $300 \mathrm{~mm}$ length and $200 \mathrm{~mm}$ width, where the cold air flows downward. Each TE has four holes drilled in the four corners used to fix the plate in the test section by bolts to hold them vertically.

The heat transfer process in the rotary air preheater is transient and consisting of two periods. The first is the heating period, whereas the thermal energy transfers from the hot gas to the TEs, or named charging mode. The second is the cooling period, whereas the thermal energy transfers from the hot TEs to the cold air.

The flow circulation system was designed to simulate the real operational sequence of the Ljungstrom preheater. A special ducting system was constructed in to allow two ways - two fluids flow, as shown in figure 2 .

The iterance and exhaust of the fluids is controlled by four gates. Two gates, no. 1 and no. 2 are for inlets and two gates, no. 33 and no. 4 are for outlets. In the heating period, the hot gases are allowed to pass and flow from underneath to up through the test section for a period of 10 seconds, which similar to that of the prototype. The flue gas leaves at the top of test section to outside of the lab. During this period, gates no. 1 and no. 3 were kept opened, while gates no.2 and no. 4 were closed to prevent the cold air to flow into the test section from the top and mix with flue gas, which is flowing up. In the cooling period, gates no.1 and 


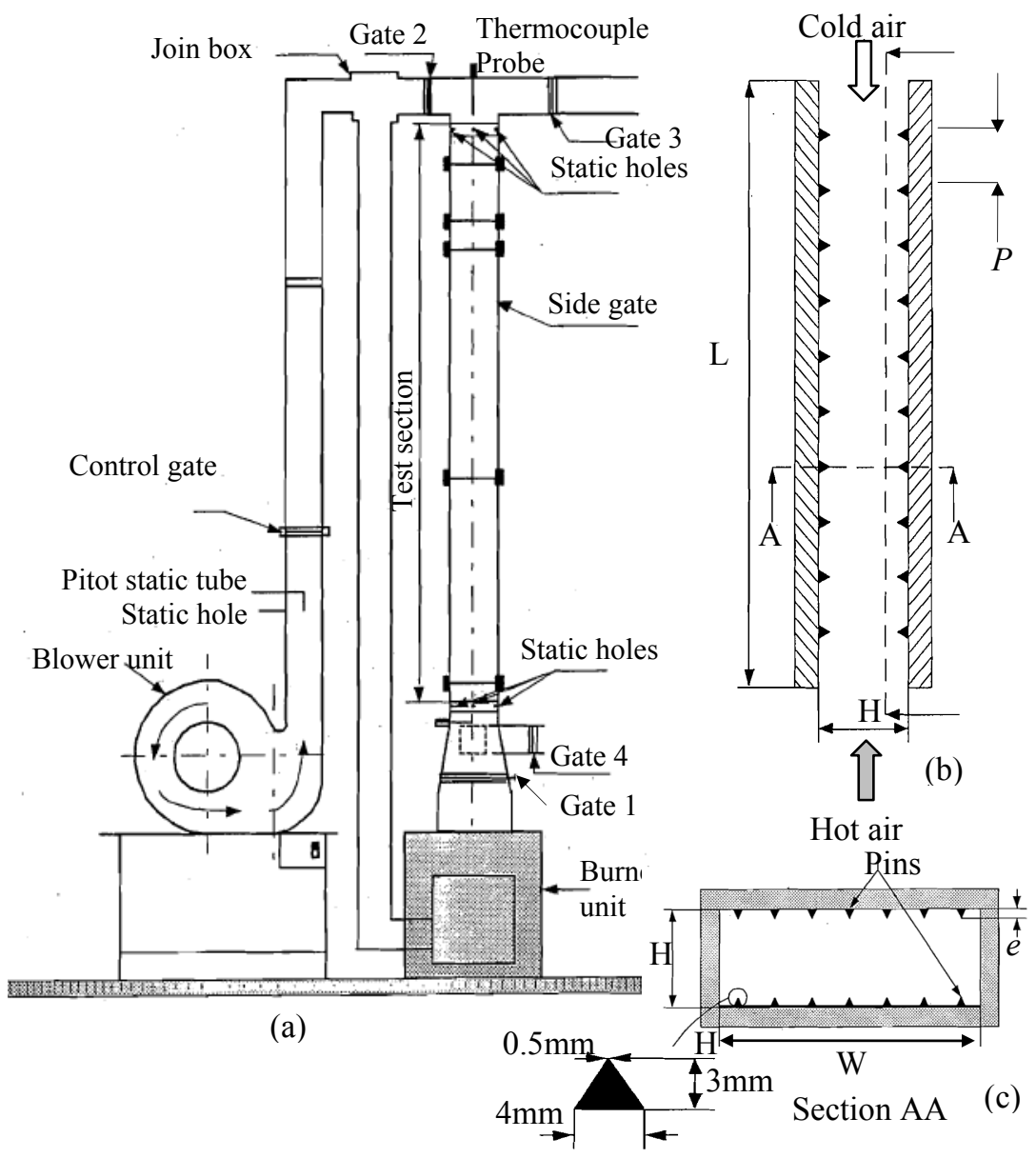

Figure 2: (a) Schematic of the experimental test rig, (b) longitudinal cross section in the test section, (c) horizontal cross section.

no. 3 were closed and gates no. 2 and no. 4 were opened. In this case, cold air was allowed to pass from the top and flow through the test section to the bottom; i.e. to the hot side of the test section. Air was then exhaust to outside of the lab. During the heating period, heat transfer from the hot gas to the thermal elements, $Q_{h}$ must be removed in the cooling period from the thermal elements to air as $Q_{c}$. Both may be evaluated by measuring the fluids flow rates and their temperature difference between inlets and outlets.

The burner unit was essential to produce high temperature gases, up to $270^{\circ} \mathrm{C}$. This unit is installed under the test section. The $750 \mathrm{~mm}$ height $\mathrm{x} 550 \mathrm{~mm}$ length $\times 250 \mathrm{~mm}$ width frame of the unit was built up by the use of special firebrick. The inside of the core was covered with metal plate to prevent leakage, while from outside, it is coated with a gypsum layer. Gas burner is used as the 
flue gas source. Air is directed from the blower to the core by the passages of the flow circulating system discussed earlier.

The measuring instruments used to collect the raw experimental data are mainly for temperature, pressure, flow rate, and velocity measurements. Seven thermocouple wires type $\mathrm{K}$ were used to measure the temperature distribution on the surface of the working element. They wires were fixed by means of high compression contact elements, as shown in figure 3. Each thermocouple wire was calibrated in-site by means of comparing with thermometer in water. Two probes were used for each fluid to measurement the temperature at inlet and outlet. The probes used were type $\mathrm{K}$ measures up to $400^{\circ} \mathrm{C}$ with accuracy of $0.1^{\circ} \mathrm{C}$. They were fixed normal to the flow direction and connected to a selector switch with digital reader. The mean value of three read-outs for each data point was considered to improve the accuracy.

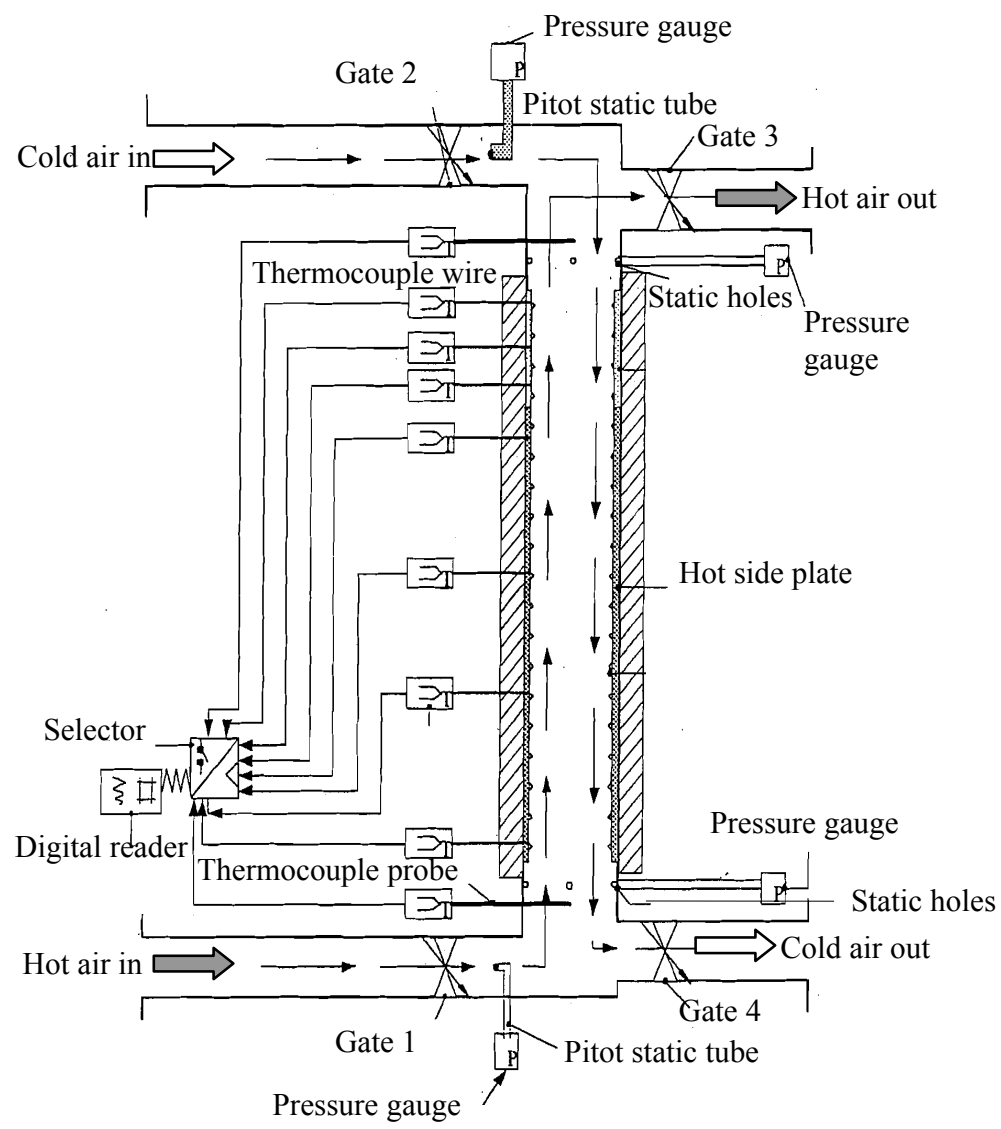

Figure 3: Flow system and locations of the data measuring locations. 
To measure the pressures and their drops between inlets and outlets of the air and the flue gases, three static holes were constructed in the wall near the inlets and outlets of the test section. The pressure taps were connected to a Umanometer. To measure the velocity of the fluids, a standard Pitot static tube was used to measure the static pressure and total pressures by means of Umanometer. All of the pressure measurements instruments were calibrated by means of comparison with standard devices. Schematic diagram of the measuring arrangement is shown in Figure 3.

\section{Experimental procedure}

Prior to the measurements, all the measuring instruments have been calibrated and subjected to accuracy analysis. In the primary checking tests, a flue gas was detected in the burner frame and in the connections of the test section with flow circuit ducting system. Necessary modifications and sealing improvements were conducted to avoid any leakage of air or flue gas. Having all the measuring instruments calibrated and the leakage problem resolved; the experimental data acquiring has been commenced. The measurements were carried out firstly with non-pinned plates, and then with different pinned plates.

The measurement procedure was carried out by first starting the burner to heat up the air. Then, gates no. 1 and no. 3 were opened to start the hot period, which took 10s. After the heating period, another 10s were allowed for cold period, where gates no. 1 and no. 3 were closed and gates no. 2 and no. 4 were opened. For the heating-cooling process to be stable and steady, the process required around 7 to 10 minutes, as experienced from previous primary tests. Various operational cases were investigated by varying the following parameters:

- Four different baskets types were tested by changing the number of TEs in the test section as $12,10,8$, and 6 TE. Consequently, the hydraulic diameter, $D_{h}$ would change.

- For each basket type, the flow rates of the hot and cold fluids were varied. This was achieved by controlling the area of the blower discharge at $100 \%$, $90 \%, 80 \%, 70 \%$, and $60 \%$ opening.

- Changing of the discrete projection configuration by constructing different TEs having various pin-to-pin distances. This provides different pitch-toheight ratios, $P / e$ which, for the present investigation were selected as 16.67 , 12.5 , and 10 .

\section{Analysis of experimental measurements}

The enhancement of heat transfer by artificial roughing is always combined with penalty of high pressure loss. Hence, the performance evaluation of the thermal systems with fluid flow must take into account the hydraulic and the thermal functionality, simultaneously. The frictional resistance was evaluated by the well known Darcy-Wistbach equation, as 


$$
f=\frac{\Delta p}{\left(\frac{L}{D_{h}}\right) \rho\left(\frac{v^{2}}{2}\right)}
$$

where $\Delta p$ is the measured pressure drop across the test section, which having length, $\mathrm{L}$ and hydraulic diameter, $D_{h}$. The mean velocity in the passage between the thermal elements, $v$ could be obtained from the measured flow rates of the air/hot gases passing through the cross sectional area between two thermal elements, $A(=w \mathrm{x} s)$. Equation 1 was used to evaluate the friction factors, $f_{o}$ for the non-pinned case and $f_{p}$ for the pinned plates cases. The hydraulic diameter, $D_{h}$ is evaluated as:

$$
D_{h}=4 \cdot w \cdot s / 2(w+s)
$$

where $s$ is the distance between two adjacent TEs.

It is quite common to use Stanton number, St values as indicator for the convective heat transfer performance, as:

$$
\mathrm{St}=\mathrm{Nu} / \mathrm{Re} \cdot \mathrm{Pr}
$$

Nusselt Number is evaluated as:

$$
\mathrm{Nu}=h \cdot D_{h} / k_{f}
$$

The fluid, here, may be air in the discharging mode, and hot gases in the charging mode. $\mathrm{Nu}_{\mathrm{o}}$ is referring for the case of smooth heating elements, and $\mathrm{Nu}_{\mathrm{p}}$ is referring to the case of pinned heating elements. Consequently, this will produce $\mathrm{St}_{\mathrm{o}}$ and $\mathrm{St}_{\mathrm{p}}$ for the smooth elements and the pinned elements cases, respectively. The convection heat transfer coefficient, $h$ is predicted by Newton cooling law:

$$
h=Q / A_{s} \cdot \Delta T
$$

$\Delta T$ is equal to $\left(T_{f}-T_{w}\right)$ in the charging mode and is equal to $\left(T_{w}-T_{f}\right)$ in the discharging mode. The wall temperature, $T_{w}$ is the mean of seven locations in the thermal elements and the fluid temperature, $T_{f}$ is calculated as the mean of the measured fluid temperatures at the inlet and outlet of the test section, $\left(=0.5\left(T_{\text {fin }}\right.\right.$ $\left.+T_{\text {fout }}\right)$ ). The heat transfer, $Q$ was estimated experimentally from

$$
Q=m_{f} C_{p . f} \Delta T_{f}
$$

where $m_{f}$ is the measured flow rates of the fluids and $\Delta T_{f}$ is the measured temperatures difference between inlet and outlet.

\section{Discussion of results}

The results were obtained with correspondence to the varied parameters mentioned earlier and grouped accordingly and were classified accordingly. For each one of the four tested baskets, the results are presented for three different cases of pitch-to-height ratios, $P / e$. Two thermal processes were studied, firstly is 
the charging mode and secondly, the discharging mode. The discussion will be conducted by grouping the results into four different cases with reference to the basket types identified in table 1 .

Table 1: $\quad$ Summery of measured parameters.

\begin{tabular}{|c|c|c|c|}
\hline $\begin{array}{c}\text { Case based on } \\
\text { No. of TEs }\end{array}$ & $\begin{array}{c}\text { Roughening } \\
\text { patterns, } P / \boldsymbol{e}\end{array}$ & $\begin{array}{c}\text { Operation } \\
\text { modes }\end{array}$ & $\begin{array}{c}\text { Range of } \mathbf{R e} \\
\mathbf{x ~ 1 0}\end{array}$ \\
\hline \multirow{2}{*}{ Case 1: 12 TE } & $16.67,12.5,10$ & Charging & 1.68 to 2.36 \\
\cline { 3 - 4 } & & Discharging & 0.575 to 0.85 \\
\hline \multirow{2}{*}{ Case 2: 10 TE } & $16.67,12.5,10$ & Charging & 0.9 to 3.38 \\
\cline { 3 - 4 } & & Discharging & 0.718 to 0.93 \\
\hline \multirow{2}{*}{ Case 3: 8 TE } & \multirow{2}{*}{$16.67,12.5,10$} & Charging & 1.015 to 1.34 \\
\cline { 3 - 4 } & & Discharging & 0.965 to 1.3 \\
\hline \multirow{2}{*}{ Case 4: 6 TE } & \multirow{2}{*}{$16.67,12.5,10$} & Charging & 1.38 to 1.79 \\
\cline { 3 - 4 } & & Discharging & 1.306 to 1.808 \\
\hline
\end{tabular}

To compare the effect of the thermal process performance, the results are presented in form of Stanton number ratio, $\mathrm{St}_{\mathrm{p}} / \mathrm{St}_{\mathrm{o}} \sim \mathrm{Re}$. Figures 4 and 5 show the enhancement in heat transfer for all basket cases in the charging mode and discharging mode, respectively. The general trend for all tested baskets is similar

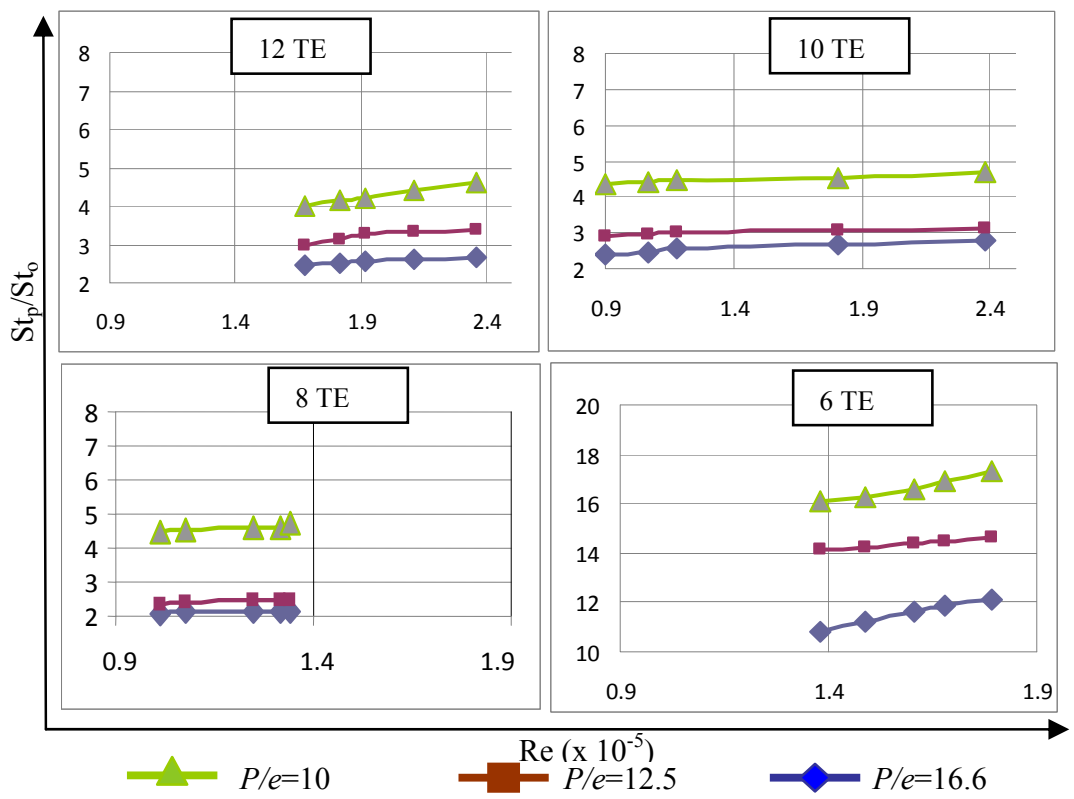

Figure 4: Stanton number ratios versus Re in the charging mode, for various design conditions. 


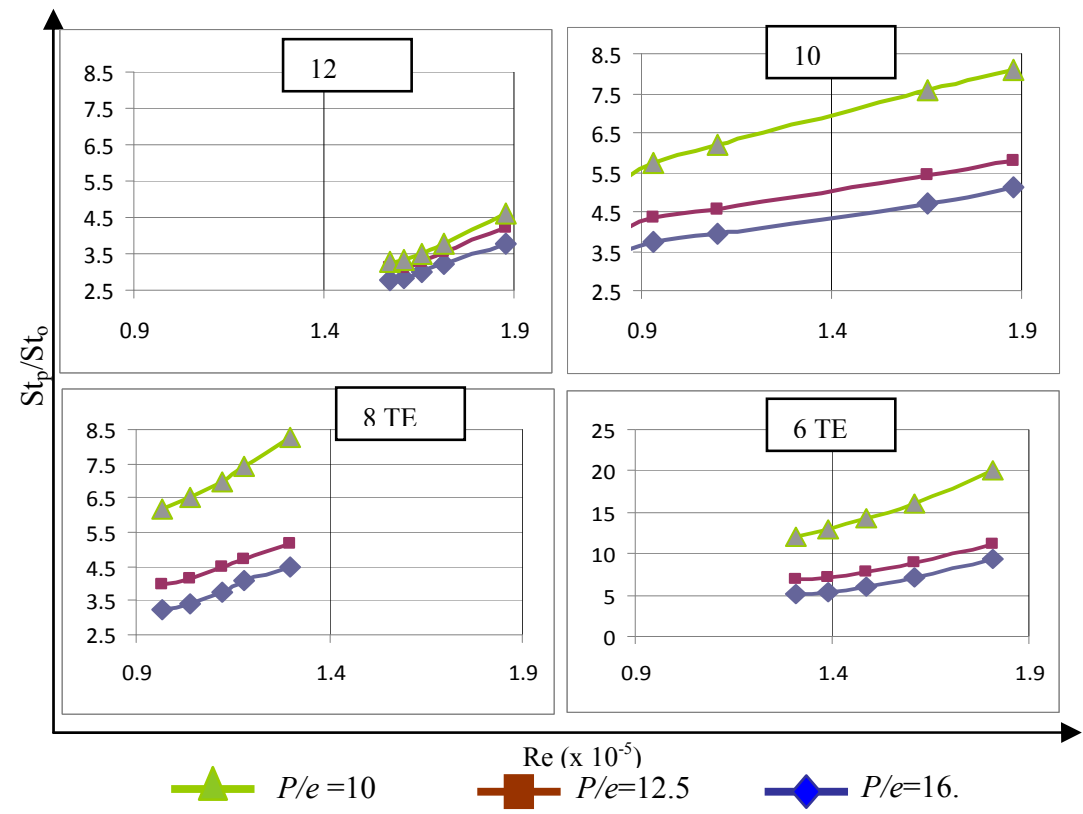

Figure 5: $\quad$ Stanton number ratios versus Re, in the discharging mode.

in considering the effect the number of pins in the TE. The highest enhancement was occurred in the case of larger number of ribs in the TE, i.e. at $P / e=10$. It is revealed that as the concentration of the pins in the HE reduces, the thermal enhancement reduces. The $\mathrm{St}_{\mathrm{p}} / \mathrm{St}_{\mathrm{o}}$ ratio reduces as the number of TEs increases in the basket. This means that narrowing the flow passages will reduce the thermal enhancement.

When comparing the thermal enhancement results in the charging mode with corresponding results in the discharging modes, it is quite clear that the release of the thermal energy from the TEs to the cold air is more efficient with use of the pins compared with the smooth case. This could be realized by comparing the values of $\mathrm{St}_{\mathrm{p}} / \mathrm{St}_{\mathrm{o}}$ at the same Re for the same basket.

In all cases of $P / e$ ratio, higher values of $\mathrm{St}_{\mathrm{p}} / \mathrm{St}_{\mathrm{o}}$ was obtained at larger concentration of pins in the TEs. In case of $P / e=10$, the maximum values of $\mathrm{St}_{\mathrm{p}} / \mathrm{St}_{\mathrm{o}}$ were obtained in the charging mode as $17.3,4.71,4.7$, and 4.6 in baskets of $6,8,10$, and 12 TEs respectively. In the discharging mode, the maximum enhancements in the thermal process were 20.06, 8.3, 8.0, and 4.62 in baskets with $6,8,10$, and 12 TEs, respectively.

The penalty paid as pressure drop due to frictional losses is shown as $f_{p} / f_{o}$ in figures 6 and 7 for the charging and discharging modes, respectively. It was observed that the losses are becoming higher as the number of pins increased in the TEs, which indicated by lower values of $P / e$ ratio. In all measured cases, higher values of $f_{p} / f_{o}$ were measured at $P / e=10$. 


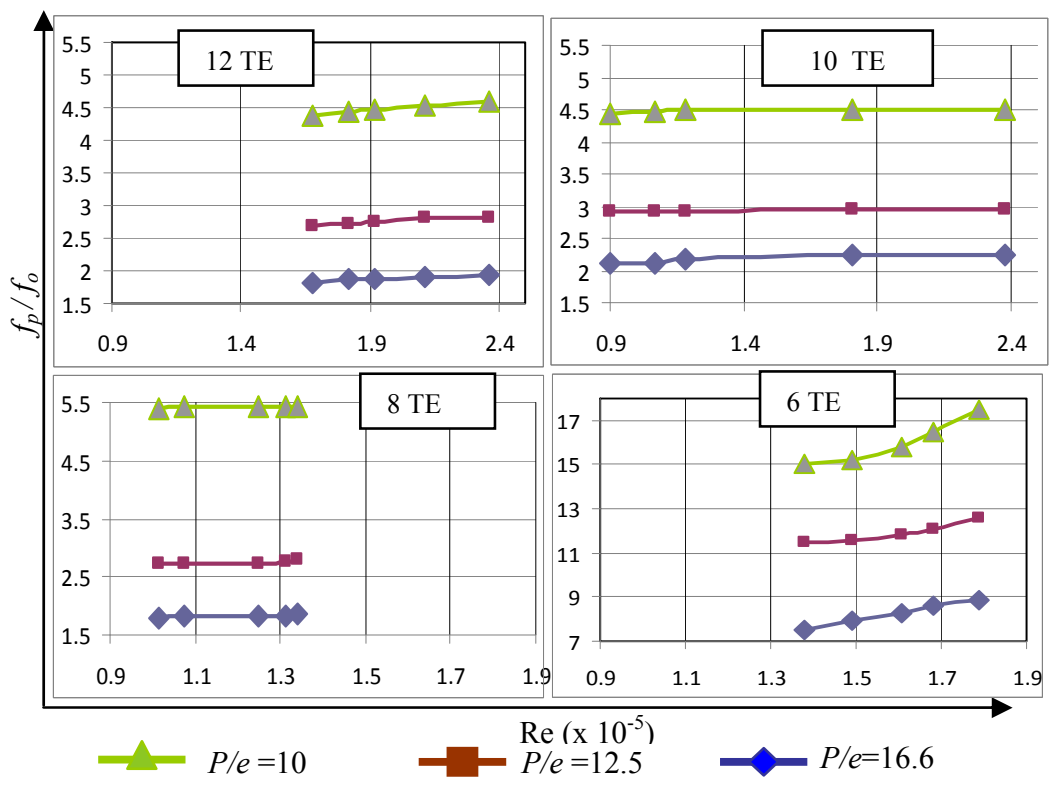

Figure 6: Friction ratios versus $\mathrm{Re}$, in the charging mode various design conditions.

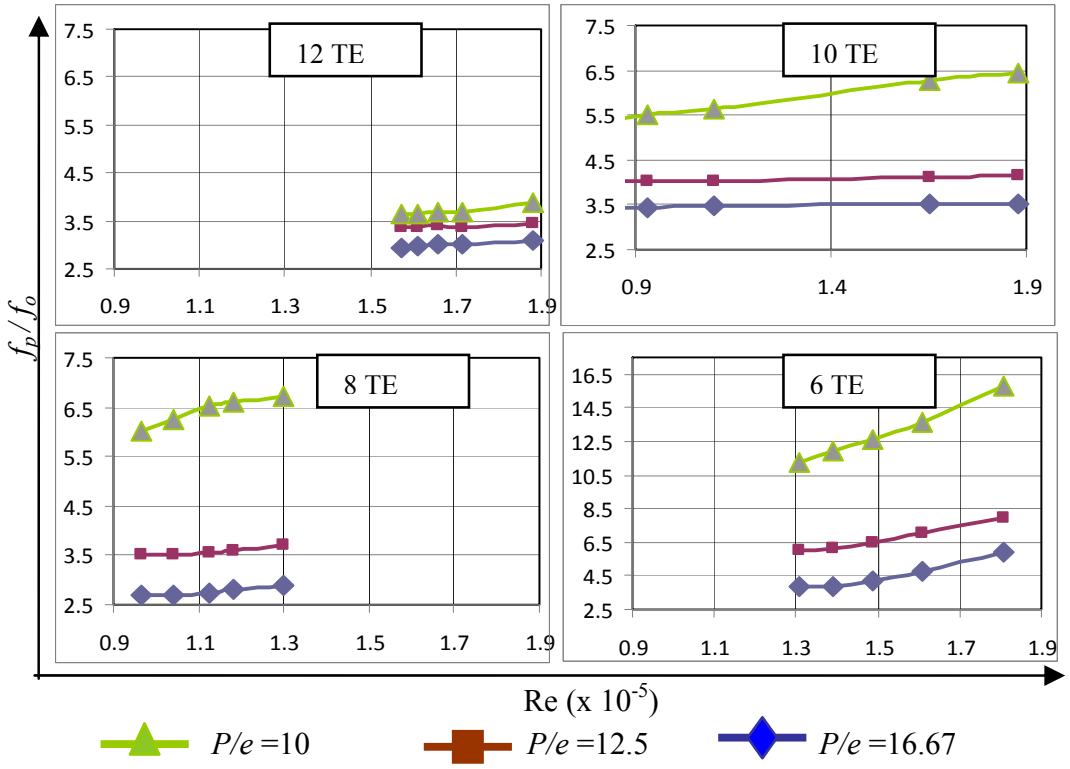

Figure 7: Friction ratios versus Re, in the discharging mode for various design conditions. 
In both, charging and discharging, the friction factor ratios were increasing as the number of TEs installed in the basket is reduced. The maximum values of the friction ratio were recorded for baskets with 6 TEs, while those are reduced to their minimum as the heating elements were increased to 12 , which is the highest tested number of TEs/basket.

The combination of the hydrothermal performance enhancement by using the pin discrete projection is presented as the efficiency index, EI, as:

$$
E I=\left(\mathrm{St}_{\mathrm{p}} / \mathrm{St}_{\mathrm{o}}\right) /\left(f_{p} / f_{o}\right)
$$

The results are shown in figures 8 and 9 for the charging and discharging cases, respectively. In general, the thermal enhancement improves the overall performance of the system by using the pin shape turbulators, where the estimated values of EI are higher than 1.0.

However, when number of the TEs increased to 12 in the basket, values of the EI were reduced to around $0.95 \pm 0.03$ at $P / e=10$. This means that the frictional losses become more effective than the thermal enhancement when large number of pins produced in the TEs in narrow passages. Taking the increase of the induction fans into consideration, the selection of the $P / e$ produces the best improvement in the performance at all types of the baskets.

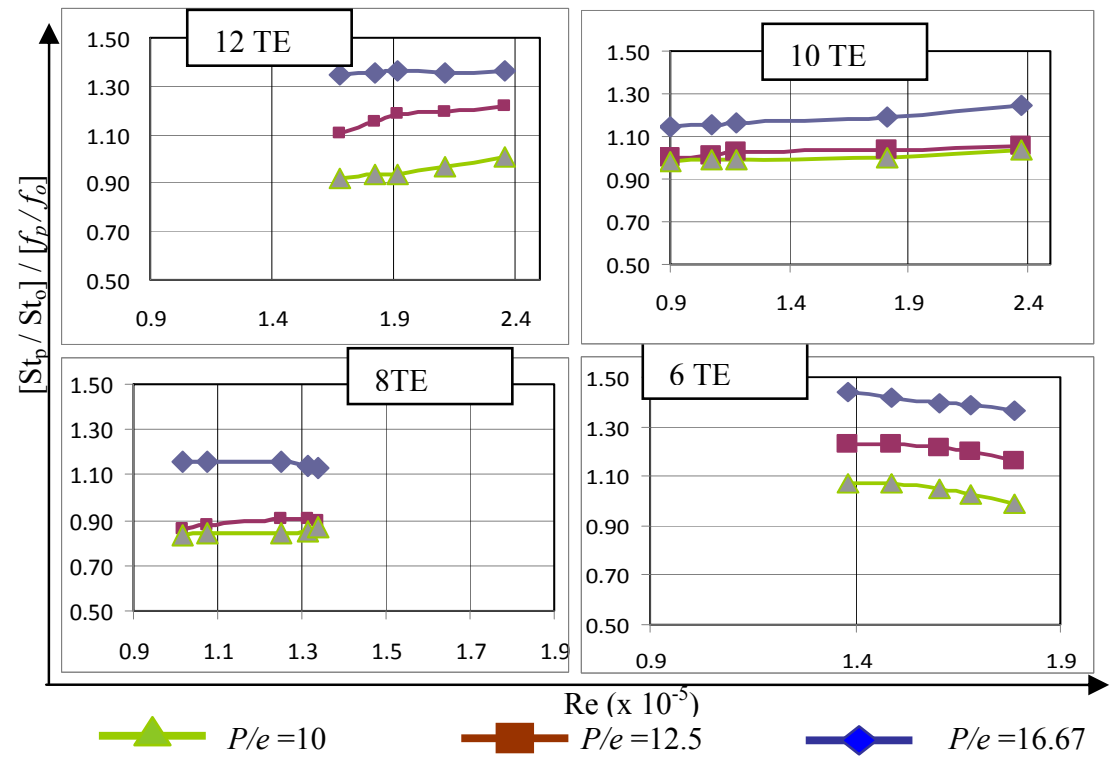

Figure 8: Efficiency index variation versus Re, in the charging mode for various design conditions. 


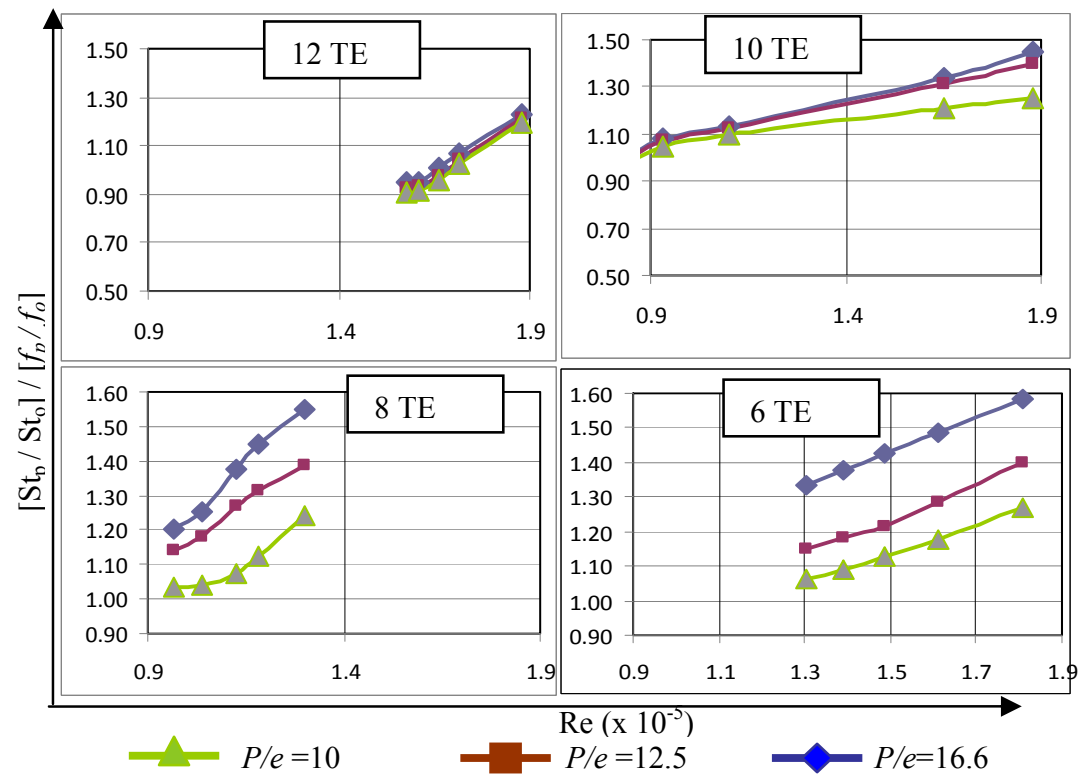

Figure 9: Efficiency index variation versus Re, in the discharging mode for various design conditions.

\section{Conclusion}

An experimental test rig has been designed and constructed to simulate the Ljongstrom rotary air preheater system, The rig was used to investigate the performance of the system in the thermal energy charging and discharging operational modes, using artificially roughened thermal element by pin shaped discrete. . The investigation was carried out at various baskets designs including different thermal elements in the basket and different pin pitch-to-height ratios. The heat transfer enhancement and the pressure drop due to the frictional losses were measured and presented at various Reynolds numbers. The results indicated that the artificial roughening by pins enhanced the performance based on efficiency index values. Larger enhancement results were obtained with $P / e=10$ compared to the 12.5 and 16.67 ratios. Considering, thermal enhancement and pressure losses simultaneously, the efficiency index show better performance at $P / e=16.67$. The discharging process shows average enhancement about 1.4, while it is about 1.2 in the charging mode.

\section{Acknowledgements}

The authors acknowledge the Ministry of Electricity - Iraq for granting the research. Also, Universiti Teknologi PETRONAS is acknowledged for the financial and technical support to present and publish the paper. 


\section{Nomenclature}

\begin{tabular}{|c|c|c|c|}
\hline$A_{s}$ & Surface area, $\left(\mathrm{m}^{2}\right)$ & $T$ & Temperature $\left(\mathrm{C}^{\mathrm{o}}\right)$ \\
\hline$C_{p . f}$ & Specific heat of fluids, $(\mathrm{kJ} / \mathrm{kg} . \mathrm{K})$ & $v$ & Mean velocity, (m/s) \\
\hline$D_{h}$ & Hydraulic diameter, (m) & & \\
\hline$e$ & The pitch height, (m) & $\mathrm{Nu}$ & Nusselt number \\
\hline$f$ & Friction factor & $\operatorname{Pr}$ & Prandtl number \\
\hline$H$ & Width of the test section (m) & $\mathrm{Re}$ & Reynolds number \\
\hline$h$ & $\begin{array}{l}\text { Coefficient of convective heat } \\
\text { transfer } \mathrm{W} / \mathrm{m}^{2} \mathrm{~K}\end{array}$ & St & Stanton number \\
\hline$k_{f}$ & Thermal conductivity of fluids & & \\
\hline$L$ & Total height of the test section, $(\mathrm{m})$ & $\mathrm{HEX}$ & Heat Exchanger \\
\hline $\mathrm{m}$ & Mass flow rate $\mathrm{kg} / \mathrm{s}$ & RAPH & Rotary Air Pre Heater \\
\hline$p$ & Pitch, $(\mathrm{m})$, pressure, $\left(\mathrm{N} / \mathrm{m}^{2}\right)$ & TE & Thermal Element \\
\hline$Q$ & Rate of heat transfer (Watt) & & \\
\hline$s$ & Distance , (m) & $\rho$ & Density of fluids \\
\hline
\end{tabular}

\section{References}

[1] Shah R. A. , classification of Heat Exchangers, "Two Phase Flow Heat Exchanger thermal and Hydraulic design", Eds. Kakac, Bergts, A. E. and Scientific Affairs Division Applied Sciencer, Vol. 143, pp. 9-45. 1981.

[2] Hilmer, K. and Sven, H., Heat transfer and fluid resistance in Ljunstrom regenerative-type air preheaters, Transuction of ASME, pp.61-72. Jan.1943.

[3] Ghodsipour, N. and Sadrameli, M., Experimental and sensitivity analysis of a rotary air heater for the flue gas heat recovery, Applied Thermal Engineering 23, pp.571-580. 2003.

[4] Skiepko, T. and Shah, R. K., A comparison of rotary regenerator theory and experimental results for an air preheater for a thermal power plant. Experimental thermal and fluid Science, 28, pp. 257-264. 2004.

[5] Wu Z., Melnik R. V. N., Borup, F., Model-based analysis and simulation of regenerative heat wheel. Energy and Building, V. 38, pp.502-514. 2006.

[6] Drobnič B., Oman Janez, and Tuma Matiji, A numerical model for the analysis of heat transfer and leakages in a rotary air heater. Inte. J. Heat and Mass Transfer 49, pp 5001-5009. 2006.

[7] Wang, F.Y., Zhao, L.L., Zhou, Q. T., Xu, Z. G., and Kim, H. T., Exergy analysis on the irreversibility of rotary air preheater in thermal power plants, Energy, 33, pp. 647-656. 2008.

[8] Stasiek, J.A., Experimental studies of heat transfer and fluid flow across corrugated-undulated heat exchanger surfaces. Int. J. Heat and Mass Transfer, V.41, No. 6-7, pp.899-914. 1998.

[9] Han, J.C. and Dutta, S., "Internal convection heat transfer and cooling: an experimental approach," von Karman institute for fluid dynamics, lecture series on heat transfer and cooling in gas turbine, Belgium, May 8-12, 1995. 
[10] Han, J. C., Recent studies in turbine blade cooling, International journal of rotating Machinery, V. 10. No.6, pp. 443-457. 2004.

[11] Webb, R. L. and Perez-Blanco, Enhancement of combined heat and mass transfer in vertical tube heat and mass heat exchanger, Transaction of the ASME, V. 108, pp. 70-75. 1986.

[12] Han, J.C., Dutta, S., and Ekkad, S.V., Gas Turbine Heat Transfer and Cooling Technology, Taylor \& Francis, pp. 289, 2000. 